\section{Original} Article

\begin{tabular}{|l|}
\hline Access this article online \\
\hline $\begin{array}{l}\text { Website: } \\
\text { www.ajobe.org }\end{array}$ \\
\hline DOI: \\
10.4103/1817-7417.86027 \\
\hline Quick Response Code: \\
\hline
\end{tabular}

Address for Correspondence: Dr. E. Boshoff,

Department of Industrial Psychology, P.O. Box 339 Faculty of Economic and Management Sciences,

University of the Free State, Bloemfontein 9300, South Africa E-mail: boshoffe@ufs.ac.za

\title{
The conceptualization and measurement of philosophical approaches that influence ethical decision making in the work context: Part 1
}

\author{
Estelle Boshoff, Martina Kotzé
}

Department of Industrial Psychology, Faculty of Economic and Management Sciences, University of the Free State, Bloemfontein, South Africa

\section{ABSTRACT}

The negative consequences which unethical behaviour holds for organizations necessitates a focus on ethical issues within the work context, as well as factors which may have an influence on ethical behaviour. Regarding individual factors, researchers indicate that the individual's ethical decision-making philosophy influences the manner in which ethical problems are managed and behavioural decisions are made. The aim of this article (which forms part of a research project consisting of four parts) is therefore to investigate, by means of a thorough literature review, the ethical issues that organizations mostly face, as well as the philosophical decision-making approaches that may influence ethical decision making in the work context, and to integrate these approaches within a holistic framework of ethical decision making. Six main philosophical approaches together with certain corresponding sub-approaches that may influence ethical decision making in the workplace were identified and integrated within a holistic framework of ethical decision making.

Key words: Unethical/ethical behaviour, Work ethics, Ethical decision-making, Ethical issues in the work context, Philosophical approaches that influence ethical decision-making

\section{INTRODUCTION}

According to De Koker (2007) and Squire (2007) there appears to be a decrease in the level of ethical behaviour in international as well as South African organizations. Crime, mostly in the form of fraud and corruption, appears to be a worldwide problem (Rabl and Kühlmann, 2008), and occurred in one out of every two organizations during the period 2005 to 2006 (Economic crime: people, culture and controls, 2007). South Africa is no exception in this regard, and is seen as the country with the highest whitecollar crime worldwide. De Koker (2007) states in this regard that crime has reached unacceptable levels in South Africa. In spite of the attention devoted to crime, the levels of economic crime and the financial and non-financial consequences thereof have increased (Economic crime: people, culture and controls, 2007). An average of 23 cases of fraud per year was reported in South African organizations for the period 2006 to 2007, with an average loss of income of R7.4 million for that period (SA, Capital of white-collar crime, 2007). Unethical behaviour does not only hold dire financial consequences for organizations, but subsequently may also lead to other negative consequences such as negative media exposure, low morale and high employee turnover (Desjardins, 2006; Trevino and Nelson, 2007).

Although different perspectives may avail to what ethical or unethical behaviour entails, ethics can be seen as dealing with fairness, decisions regarding right and wrong, as well as the definition of rules which provide the basis for responsible behaviour. Ethical behaviour includes behaviour which ensures that the defined rules are consistently applied in mundane situations /Connock and Johns in Orme and Ashton, 2003; Orme and Ashton, 2003). Similarly, work ethics can be defined as the acceptability or the unacceptability of behaviour within an organization, at a specific time and within a specific cultural environment (Svensson and Wood, 2003). Work ethics can also be 
seen as the behavioural standards within the business context which are consistent with the principles, norms and standards of business practices, as agreed with the community (Trevino and Nelson, 2007), and which further the interests of all who are influenced by the business world (Rossouw and Van Vuuren, 2004).

Regarding the factors that may influence ethical decisionmaking within the world of work, research from Stead, Worrel and Stead (1994) supports a person-situationinteraction approach to ethical decision-making. According to this approach both individual and situational factors influence the decisions that are made within organizational contexts (Stead et al., 1994; Van Zyl and Boshoff, 2010). From an individual perspective, researchers indicate that individuals' ethical decision-making philosophies influence the manner in which ethical problems are managed and behavioural decisions are made. Individuals' ethical philosophies are represented by their ethical frames of reference, consisting of the ethical norms and principles which they hold. Since individuals face moral decisions daily, these decisions centre around questions regarding right or wrong. Thus, ethics provides the basis according to which these decisions are made. Researchers found furthermore that individuals with different ethical decisionmaking philosophies differ in terms of the manner in which ethical information is integrated, as well as the manner in which individuals judge their ethical issues, and other moral decisions (Stead et al., 1994; Boshoff, 2009). Thus, for organizations to survive within a highly competitive global market, renewed attention should be paid to the ethical issues that organizations and individuals in the work context face, as well as the way in which ethical decisions are taken within this context.

According to Rae (1995) the existence of any community, including organizations, relies on clearly formulated ethical guidelines. One of the issues of ethics within the workplace relates to the lack of moral consensus regarding right and wrong. An important reason for this lack of consensus includes a lack of insight into the different world views and ethical paradigms on which individuals base their decisions. Thus, the questions that arise from the research project relate to (i) what the most common issues in organizations relating to ethical decision making are, (ii) what influence philosophical approaches may exert on ethical decision making within the work context, (iii) what the dominant ethical decision-making approaches mostly utilized within the work context at both organizational and individual levels are and (iv) what level of ethical behaviour individuals and organizations practice in their day-to-day decision making within the work context?

In order to explore these questions, the objectives of the research project were firstly to investigate, by means of a thorough literature review, the predominant ethical issues that organizations face and the various philosophical decision-making approaches that may influence ethical decision making in the work context. Upon completion of the literature review it became apparent that, although various philosophical decision-making approaches relating to ethical decision-making could be identified, these approaches were mostly discussed in isolation, lacking a holistic and integrated perspective on ethical decision making, specifically in the context of work. Subsequently, the second objective of this research was to categorize and integrate these philosophical approaches within a holistic framework of ethical decision making. The third objective was to develop and statistically evaluate a measurement model based on the above-mentioned philosophical approaches regarding ethical decision making.

In order to determine the dominant ethical decision-making approaches most utilized within the work context at both organizational and individual levels, and to be able to measure the level of ethical behaviour within organizations, the fourth objective of the study was to develop a work ethics questionnaire, based on the holistic framework of ethical decision-making approaches that was developed. The fifth objective of the study was to develop interventions in order to enhance ethical decision making within the work context.

In order to operationalize this research project, the following steps, adapted from Babbie and Mouton (2004, p.114), and diagrammatically presented in Figure 1, were followed:

Since this study includes several objectives, it was decided to divide the reporting of the results of the research into four parts: Part 1 reports on the results of the literature review, including the identification and conceptualization of the predominant ethical issues in the work context as well as the main philosophical approaches of ethical decision making, and the integration of these philosophical approaches within a holistic framework of ethical decision making. Parts 2 and 3 report on the development and statistical evaluation of a measurement model based on

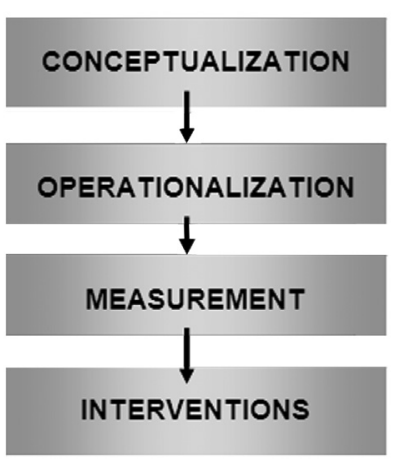

Figure 1: Steps followed which form part of the measurement process within a structured scientific study (Adapted from Babbie and Mouton, 2004, p. 114) 
the above mentioned framework, as well as the reporting on the development and statistical evaluation of the questionnaire developed in order to measure the most dominant philosophical decision-making approach utilized by a specific organization or individual, as well as the level of ethical behaviour within the organization. Part 4 includes a discussion on the interventions developed in order to enhance ethical behaviour as measured by means of the questionnaire.

This article encompasses part 1 of the above-mentioned structure and therefore the purpose of the article is the identification and conceptualization of the predominant ethical issues in the work context as well as the main philosophical approaches of ethical decision making, and the integration thereof within a holistic framework of ethical decision making. Furthermore, the implications of the research for organizations are discussed, and recommendations for future research are made.

\section{ETHICAL ISSUES IN THE WORK CONTEXT}

Any action within a specific organization has an impact on everyone within the organization as well as those individuals who do business with the organization. Actions are never ethically neutral, but are always ethically charged and can thus impact positively or negatively on the interests and welfare of others (Rossouw, 2002). Therefore, any organization has stakeholders towards whom they have an ethical responsibility. Stakeholders refer among others to the consumer, the community, the employees as well as shareholders (Malan and Smit, 2001; Garriga and Melé, 2004).

Hereafter, a discussion of general ethical issues in the work place with specific focus on: the organization and the consumer, community and shareholders; the organization and the environment; ethical issues arising from the organization/management - employee interaction; ethical issues arising from the employee - organization/ management interaction.

\section{The organization and the consumer, community} and shareholders

Although one of the goals of an organization is to make a profit, organizations cannot exist in isolation. In order to make a profit a service or a product must be delivered to others, which places the organization in a relationship with the community. In doing so the organization serves the interests of others and these interests must be respected as such (Rossouw, 2002). Therefore, the organization has a responsibility towards everyone affected by the organization's decisions, among which are the shareholders, consumers, employees and the community (Desjardins, 2006). Although one of the goals of the organization is to make a profit, organizations still have a social and ethical responsibility towards consumers and the community. The following examples of ethical issues which generally appear in the literature are briefly highlighted.

Safety of consumers (product safety)

The poor quality of products, as well as product safety, is an ethical issue which comes to light daily. Product safety has also become an important policy in most developed countries. Manufacturers therefore have a moral responsibility and a moral duty to deliver safe products. Should consumers not be fully enlightened regarding the characteristics of products, they may purchase dangerous products or take risks they otherwise would not have, had they been fully enlightened (Marette, Bureau and Gozlan, 2000; Trevino and Nelson, 2007).

Reasonable prices and the honest introduction of products to the community

Honesty rests on the ethical principle that the individual will not pervert the truth by deliberate misrepresentations, lies, fraud, or deception. Honesty is of cardinal importance especially in countries where large amounts of unsophisticated and illiterate consumers are concerned. Organizations must guard against exploiting consumers for their own gain. Organizations must therefore ask themselves the following ethical questions regarding products, namely whether the ignorance of consumers is not being exploited and whether the prices of products are fair (Desjardins, 2006).

\section{Protection of clients' privacy and confidentiality}

Privacy and confidentiality is a basic right of any client. Privacy as well as the duty of the organization to keep the client's information confidential does not only apply to financial information. For example, it also refers to information to do with purchases, transfers and retrenchments. No information may thus be made known to a third party if it would enable the party to identify the client, whether an organization or individual (Trevino and Nelson, 2007; Ashley, Powers and Schunter, 2009).

\section{Honesty regarding advertisements}

The goal of advertisements is to provide information regarding products and services to consumers in order to enable them to exercise appropriate choices between different products. Organizations however mislead consumers with regard to what their products can really do by making false representations and misleading assumptions. This takes place as organizations withhold important information in the advertisements and provide vague information thereby preventing their liability should the product not be capable of doing what it is meant to do. Organizations also place false and misleading information in fine print and neglect to inform consumers regarding the negative effects a product may have on an individual and the environment (Malan and Smit, 2001; McCall, 2006). 


\section{Shareholders}

Apart from the aforementioned responsibilities of organizations towards consumers and the community, organizations also have an ethical responsibility towards shareholders. The interests of shareholders are ignored by organizations in the following ways (Malan and Smit, 2001): management does not have a long-term vision for the organization; the organization's policies and strategies are driven solely by internal needs; management is insensitive or disregards the needs of shareholders; management is dishonest or does not possess the necessary integrity (Malan and Smit, 2001).

\section{The organization and the environment}

According to Desjardins and McCall (1996), business activities result in many environmental problems, among which are air and water pollution, dumping of wastes that are harmful to the environment, soil erosion and the destruction of ecosystems. Gibson (2007) indicates that work ethics therefore does not only involve individuals (whether as consumer, employee or within a community), but also includes issues regarding the environment. Organizations therefore have a responsibility towards the environment (Desjardins and McCall, 1996; Gibson, 2007). It is the responsibility of all, including organizations, to ensure that the environment survives. Organizations must not isolate themselves from participation in actions to solve environmental problems. Organizations possess special knowledge, expertise and resources which are invaluable in dealing with environmental crises. Society needs the ethical vision and cooperation of all role players to ensure the survival of the earth (Trevino and Nelson, 2007).

\section{Ethical issues arising from the organization / management: Employee interaction}

An organization's human resources, in other words the employees who make up the organization, is any organization's most important and expensive investment and is the cornerstone of the organization's success or failure. The main focus of management is therefore to keep qualified employees by creating a work environment for them within which they are valued and treated fairly, and therefore wish to work harder in and be more creative in (Trevino and Nelson, 2007). Individuals who enjoy coming to work are usually more productive than those who believe that their contributions and ideas are not deemed to be of importance. Productivity, which forms the basis of competition, can only exist when employees believe that management respects them, and only if they have respect for each other, in other words when they feel a commitment to their work. Human resource issues refer to ethical problems which occur when individuals work together. Fairness is thus central with regard to such issues. For employees, fairness does not only involve the outcomes (remuneration and promotion for example) which they receive. For employees the fairness of the decision-making process and the interpersonal treatment which they receive is of equal importance. An organization which uses fair procedures, and which treats employees with sensitivity, carries a powerful message to all employees that they are deemed important members of the community (Trevino and Nelson, 2007).

Human resource managers in South Africa as well as internationally agree that traditional personnel approaches, where focus is placed on instructions and control, have made way for new approaches characterized by greater employee engagement, cooperation and communication (Grobler, Wärnich, Carell, Elbert and Hatfield, 2002). The following ethical issues regarding the organization/ management - employee interaction figure into this framework of decentralization with the emphasis on innovation and freedom.

\section{Rights of employees}

Employee rights can be divided into legal rights and moral rights with regard to work. Individual freedom, prosperity, security, health and happiness form the core of moral rights. Legal rights include, among others, the right to a minimum wage, equal opportunities and to belong to a union (Desjardins, 2006). Employee rights are important as employees are usually in a subordinate position to their employers. This inequality results in an opportunity for different types of exploitation, such as inadequate remuneration, discrimination and invasion of employees' privacy (Rowan, 2000).

\section{Recruitment, selection and placement}

The appointment of an individual within an organization has an important impact on the person's professional and personal life (Evans, 2009). It is therefore important that organizations are continuously ethical during the recruitment process. The following potentially unfair discriminatory practices may however occur during the recruitment process, namely discrimination against a potential employee, direct or indirect, on the grounds of factors such as race, gender, ethnic or social decent, sexual orientation, age, disability, religion, political beliefs, culture, language, marital status, pregnancy, or family responsibilities (Swanepoel, Erasmus, van Wyk and Schenk, 2003).

With regard to selection, the following ethical guidelines must be followed to ensure that selection of employees takes place fairly: the process must be consistent in respect of the applicant and everyone must therefore undergo the same interview procedure as well as testing; characteristics such as, for example, the applicant's religion, race, gender, age and financial limitations may not play a role during selection decisions (Cascio, 2003; Swanepoel et al., 2003).

Malan and Smit (2001) indicate furthermore that, with regard to appointments and placements, serious problems 
regarding bribery and nepotism are prevalent in South Africa. Nepotism can be defined as favouritism of family members and of individuals of the same, race, gender, religion and political party. Therefore, management must make use of methods focussed on fairness and integrity during appointments and placements.

\section{Discrimination and affirmative action}

Discrimination regarding an individual's gender, religion, nationality and age is prohibited by law. Discrimination however extends beyond only that which is prohibited by law. Should individuals from different backgrounds work together, there are automatically certain conscious and unconscious prejudices against certain groups that may occur. Discrimination therefore takes place when anything other than qualification has an influence on the way in which an employee is treated. Therefore, discrimination is an ethical issue as it is contradictory to the right which each employee has regarding fair treatment in the work place (Trevino and Nelson, 2007).

With regards to affirmative action, it is necessary to rectify the unfairness and inequity of the past in light of South Africa's history of discrimination. Affirmative action may however not mean reverse discrimination. Affirmative action must be seen as a temporary intervention to rectify the consequences of discrimination in order to enable individuals to compete on the same level in the long run (Rossouw, 2002).

\section{Performance management}

Management has an ethical responsibility during the execution of their performance management duties. The following ethical guidelines underlying the performance management process are highlighted. Management must be clear regarding what will be measured, in other words regarding what the critical indicators of performance are (Malan and Smit, 2001). Grobler et al. (2002) add to this by indicating that prior to the occurrence of performance management, management must develop and communicate clear standards according to which subordinates will be judged. Managers must therefore be trained so that fair and accurate assessments can be made. Assessments must also be communicated effectively to employees. Unfair assessments may lead to complaints of discrimination and a loss of employee morale and productivity (Grobler et al., 2002).

\section{Remuneration}

Management frequently remunerates employees for the achievement of goals without paying any attention to the manner in which goals were reached. As individuals exhibit behaviour that is remunerated, it is important that management ensures that performance goals are realistic and achievable without employees having to behave unethically (Trevino and Nelson, 2007). Another ethical issue regarding employee remuneration concerns inadequate compensation and benefits. In this regard,
Esterhuyse (1991) places emphasis on the virtue of justice with specific reference to fair remuneration packages for employees. Employees have the right to fair remuneration. Firstly, remuneration must be fair on an interpersonal level in that a system which assesses all employees in the same way with regard to aspects such as seniority and performance must be in place. Secondly, remuneration must be fair on an intrapersonal level with regard to the number of years which the individual has been in service of the organization and to what degree the individual's responsibilities increased over time. Thirdly, the individual's rights to a minimum wage must be met (Rowan, 2000).

\section{Health and safety in the work place}

One of the most common employee rights is the right to work in a safe work environment. In cases where work may place an employee's life in danger, the employee must be involved voluntarily. Vital, however, is that the employee must be fully aware of the risks involved in any post throughout (Trevino and Nelson, 2007). Therefore, employees have the right to a healthy and safe working environment. Employers must therefore, in so far as possible, provide and maintain a work environment which is safe and without risks to the health of their employees. Employers must also inform their work force of dangers in the work place (Swanepoel et al., 2003).

\section{Sexual harassment}

Two types of sexual harassment are distinguished, namely when sexual favours are a prerequisite to progress in the work place as well as a hostile work environment in which an employee feels uncomfortable as a result of unwelcome behaviours or remarks which are sexually related. The latter includes not only physical gestures, but also remarks of a sexual nature. Compliments can also be regarded as a form of sexual harassment when they embarrass an individual and serve to undermine an individual's professionalism in front of co-workers (Trevino and Nelson, 2007). Therefore, sexual harassment is an ethical issue as it infringes on the employee's right to be treated fairly and with respect.

\section{Ethical issues arising from the employee -} organization/management interaction

Value management is an unavoidable responsibility of management. Value management concerns the values which a business internalises in its organizational culture, as well as the conflicting values that may exist as a result of the activities of the business and the personal beliefs of the employee. Values can be an important contribution to success and to the contribution of a high level of performance should the employee's values correspond with the values inherent in the post. Problems may arise should there be conflict between the moral values of the individual and the values of the organization (Swanepoel et al., 2003). Hereafter, a discussion of ethical issues arising from the employee - organization/management interaction. 
Whistle blowing

Whistle blowing refers to an attempt by an employee within an organization to make known those actions of the organization considered wrong by the employee. Hence, whistle blowing is an effort to make others aware of practices that the employee considers illegal or immoral. Employees have a responsibility to bring illegal and immoral actions within organizations to light. Employees should however first follow all internal procedures and possibilities within the organization to bring the matter to light, prior to disclosing the information to the public. Should the matter still receive no attention, the employee's only option is to obtain help from outside the organization (Desjardins, 2006).

\section{Conflicting interests}

It may happen that the employee's responsibility towards the organization may be in conflict with personal interests such as making a profit or personal progress. Conflicting interests take place when the employee's personal interests result in the employee failing to take decisions which are to the best interests of the organization/employer. Conflicting interests can occur for example, when the employee undertakes to consult for a company in competition with the organization in which the employee works (Parsons, 2007).

\section{Bribery, fraud and theft}

Bribery and fraud are serious matters in various countries and cause problems for both organizations and the government (James, 2002). Employees may be guilty of various types of bribery, including the following. Employees may accept free meals, discounts, cash prizes, vacations and overseas trips for themselves and their families in exchange for something which they must do for customers or suppliers. Employees may be paid for services that are part of their normal duties, such as the issuing of ID documents and permits in order to expedite the process. Employees may also be paid for information concerning the organization to which they have access due to the fact that they are employed by the organization. Employees may also engage in the following examples of fraud, namely the use of the company transportation for private business, the allocation of contracts to themselves as well as the falsification of qualifications and credentials (Malan and Smith, 2001). Furthermore, employee theft may take on many different forms including the misappropriation of cash, the taking of office equipment as well as when personal calls and photocopies are made at the organization's expense and when the company's letterheads are used for personal purposes (Gross-Schaefer, Trigilio, Negus and Ro, 2000; Trevino and Nelson, 2007).

\section{Low productivity}

Low productivity is another example of unethical behaviour which costs organizations a great deal. If employees are unproductive they become guilty of theft. Examples of low productivity include absence from work supported by fake medical certificates; to arrive at work but slip away to attend to personal business; employees uninterested in their work together with an apathetic attitude towards work; personal interests enjoying precedence over official duties and employees who are not willing to take responsibility or take the lead and who constantly blame everyone (Malan and Smit, 2001).

The aforementioned ethical issues in the workplace necessitate the taking of certain ethical decisions by management and employees. Therefore, focus will be placed on different philosophical approaches which guide ethical decision making, and which were identified from the literature.

\section{PHILOSOPHICAL APPROACHES TO ETHICAL DECISION MAKING}

As previously stated, different authors identify different philosophical approaches regarding ethical decision making, although no framework, integrating these approaches, currently exists. Six main philosophical approaches, together with certain corresponding sub-approaches that may influence ethical decision making in the workplace can be differentiated (Figure 2), namely the consequensialistic approach (which can be subdivided into utilitarianism, altruism, egoism and vitalism); the rule-bound approach (which can be subdivided into ethical rationalism, the principle of prohibition, contractualism and rights); the rule-bound consequensialistic approach; the virtue approach; the social justice approach and relativism (which can be subdivided into ethical subjectivism and cultural relativism). Each of these approaches will hereafter be discussed in more detail.

\section{The consequensialistic approach}

The consequensialistic approach is also known as the teleological approach, derived from the Greek word 'teleos' which means 'end' or 'goal' (Rae, 1995; Pojman, 2000). According to the teleological approach, focus must be placed on the consequences of an action or decision in order to determine the moral quality thereof (Esterhuyse, 1991; Malloy and Zakus, 1995; Garofalo, 2003). According to Esterhuyse (1991) consequensialism therefore rests on the premise that no action or decision is inherently good or bad, acceptable or unacceptable. Only the consequences of the action or decision will determine the acceptability thereof. An amount of diverse interpretations and decisions regarding when an action is good or bad, acceptable or unacceptable, exist within the consequensialistic approach, and can be described as follows. The following teleological approaches can be distinguished from Figure 2.

\section{Utilitarianism}

According to Weiss (2006), Jeremy Bentham (1748-1832) and John Stuart Mill (1806-1873) are regarded as the 


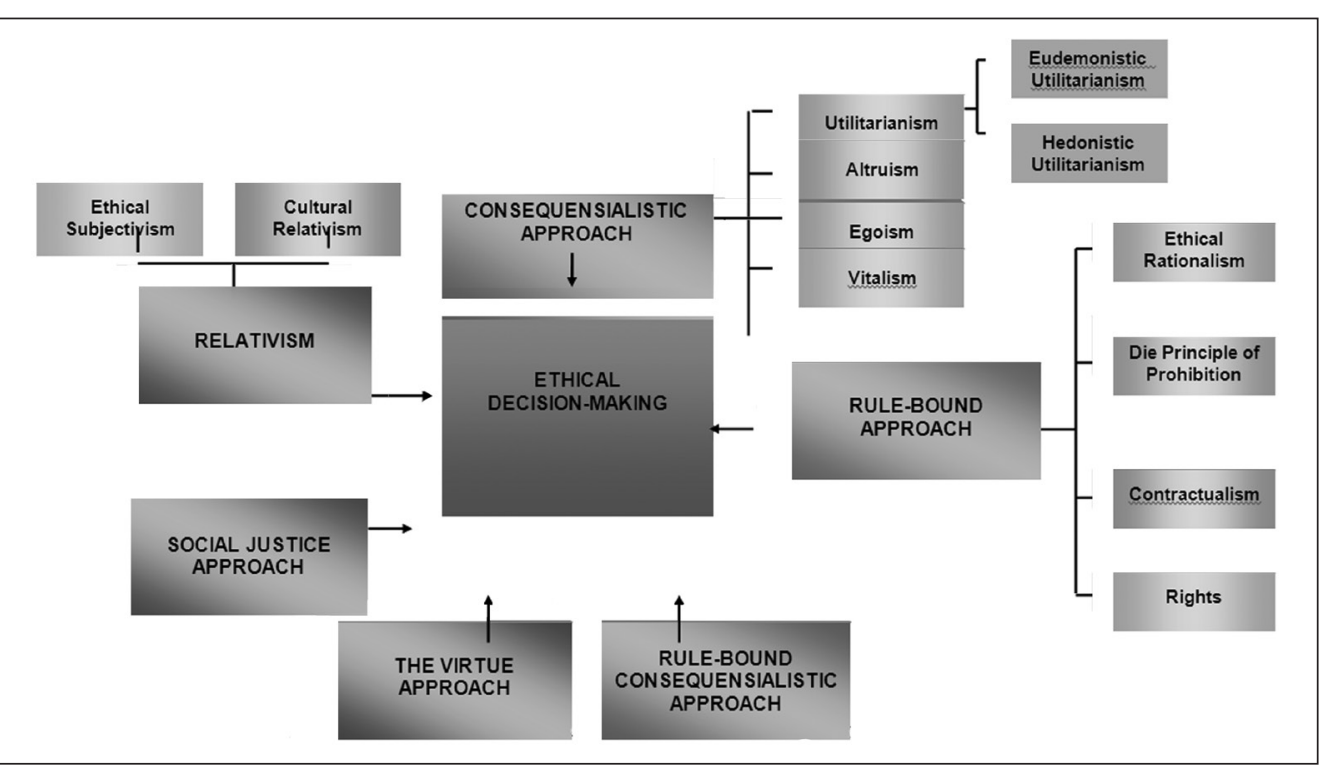

Figure 2: A holistic framework of philosophical approaches that influence ethical decision making

founders of the concept utilitarianism. Utilitarianism is based on the principle that an action or decision is moral as long as it amounts to the most good for the most people (Stead et al., 1994; Trevino and Nelson, 2007). Bentham and Mill maintain different views regarding what is meant by the concept 'most good'. According to Pojman (2000), Bentham maintains a hedonistic utilitarianistic standpoint while Mill advocates the eudemonistic vision.

Hedonistic utilitarianism is based on the premise that an action is acceptable should it involve more pleasure than pain, and is unacceptable should it involve more pain than pleasure. Therefore, the concept 'most good' is equated to 'most pleasure'. Bentham (Pojman, 2000: 38) states the following: 'Nature has placed mankind under the governance of two sovereign masters, pain and pleasure. It is for them alone to point out what we ought to do, as well as what we shall do'. Critics however are of the opinion that hedonistic utilitarianism is too simple, as other aspects which the individual attaches value to exist, such as freedom and wisdom for example.

In response to this, Mill (Pojman, 200) makes a differentiation between lower order and higher order pleasure. Lower order or elementary pleasure includes, for example, eating, drinking, resting and sensory experiences. In contrast, higher order pleasure refers to, among others, friendship, intellectual ability, spirituality, creativity, knowledge and wisdom. Mill also regards the higher order types of pleasure as superior to the lower order types of pleasure. On the grounds of this difference, Mill developed the principle of eudemonistic utilitarianism. The concept eudemonistic is derived from the Greek word 'eudaimona' which means 'happiness'. Therefore, focus is placed on the principle of happiness and not on pure pleasure. According to Rossouw and Van Vuuren (2004) as well as Rossouw, Prozesky, van Heerden and van Zyl (2006), an action is perceived by Mill as good and acceptable should it contribute to the most happiness for the most people.

\section{Altruism}

Altruism is based on the principle that each individual must only perform those actions which will be to the advantage of others, and from which the specific individual will not necessarily benefit. Therefore, the focus of altruism is not on the promotion of self-interest, but the interest of others (Sorrel and Hendry, 1994; Weiss, 2006). Weiss (2006) states that altruists will sacrifice their own personal security and safety for the advancement of others. According to Staub (n.d.) individuals' motivation to behave altruistically is based on both affection as well as personal concern for others' welfare. The affective component of altruism refers to an empathic and sympathetic disposition which directs the altruists' actions towards others.

\section{Egoism}

Egoism is based on the principle that the morality of any action is determined by the individual's self-interest. Any action which promotes the individual's self-interest is moral, and those actions which work against self-interest are viewed as immoral (Sorrel and Hendry, 1994; Rae, 1995). The philosopher Ayn Rand states the following in this regard (Rand, 1964: 27): ' $\ldots$ the achievement of his own happiness is man's highest moral purpose'. Rand maintains furthermore that egoism is the only moral approach which respects the individual's right to life. Rand provides the following justification for this standpoint. Firstly, Rand states that each human has only one life, and that this life is therefore of crucial importance. Secondly, Rand states that altruists regard the human's life as something which must 
be sacrificed in the interest of others, and that altruism therefore denies the value of the individual's life. In light of these arguments, Rand states that ethical egoism is the correct theory (Rand, 1964; Rae, 1995).

Egoists furthermore maintain the standpoint that the individual who only sees to the interests of others, strives for self destruction. According to Rae (1995) egoists base this standpoint on the following two reasons. Firstly, individuals know only their own needs and they possess a very limited ability to understand others' needs. Secondly, it is a violation of others' privacy to be concerned about their needs.

\section{Vitalism}

According to Pojman (2000), Albert Schweitzer (1875-1965) can be regarded as the founder of the vitalistic approach. Schweitzer was of the opinion that all forms of life are holy, and that the acceptability of an action or decision depends on the consequences which it may have for all the parties involved, namely people, animals and nature. According to the vitalistic principle, all parties affected by an action or decision are equally important, and therefore the consequences which an action or decision holds for one of the parties cannot be regarded as more important than, or be weighed against, the consequences which it holds for the other parties (Schweitzer, 1929; Pojman, 2000). Schweitzer therefore states the following in this regard (Schweitzer, 1929: 246-247):

'Ethics consist, therefore, in my experiencing the compulsion to show to all will-to-live the same reverence as I do to my own. There we have given us that basic principle of the moral which is a necessity of thought: It is good to maintain and to promote life; it is bad to destroy life or to obstruct it... A man is truly ethical only when he obeys the compulsion to help all life which he is able to assist, and shrinks from injuring anything that lives. He does not ask how far this or that life deserves one's interest as being valuable, nor, beyond that, whether and how far it can appreciate such interest. Life as such is sacred to him. He tears no leaf from a tree, plucks no flower, and takes care to crush no insect...'

The ability of employers and employees to determine the consequences of decisions and behaviours by means of the consequensialistic approach is critical within the organizational context. According to Appelbaum and Morison (2006), the consequences of unethical behaviour are far reaching, and influence all levels of the organization, including the decision-making process and productivity. Desjardins (2006) indicates that organizations have a responsibility to all who are affected by the organization's decisions, including shareholders, consumers, employees and society. Desjardins and McCall (1996) place emphasis on the negative consequences that business activities may have for the environment, including air and water pollution, dumping of waste which is damaging to the environment, soil erosion as well as the destruction of ecosystems. Malan and Smit (2001) add that vigilance must be kept, to ensure that that the egoistic needs of individuals or the organization as a whole, do not replace altruistic service to the greater society. In this regard it appears that vitalism, altruism, as well as utilitarianism play an important role within the organizational context.

\section{The rule-bound approach}

The rule-bound approach is also known as the deontological approach, derived from the Greek word 'deon' which means 'duty' and 'logos' which means 'logical' (Pojman, 2000). This approach rests on the premise that whether an action or decision is right or wrong, acceptable or unacceptable, depends on whether or not it complies with an accepted moral rule or universal principle (Esterhuyse, 1991; Malloy and Zakus, 1995; Rae, 1995; Kline, 2005; Gibson, 2007). Therefore, it is not the consequences of the action or decision that determine the acceptability thereof, but rules and universal principles which form a central component of ethics (Esterhuyse, 1991; Kline, 2005; Weiss, 2006; Gibson, 2007). A variety of interpretations and approaches regarding when an action or decision is right and acceptable or not exists within the deontological approach. It is apparent from Figure 2 that the following deontological approaches can be distinguished:

\section{Ethical rationalism}

According to Malloy and Zakus (1995) as well as Gibson (2007), Immanuel Kant can be regarded as one of the most prominent advocates of the rational deontological approach. Kant established an ethical approach that is not based on the consequences of an individual's actions, or on their religion, but on the individual's ability to reason (Rae, 1995). In order to achieve an in-depth understanding of Kant's vision regarding morality, it is necessary to focus on Kant's categorical imperative principle. Kant uses the term categorical imperative to refer to a universal and objective law, which applies to all rational people, in all situations (Kant, 1937; Rossouw and Van Vuuren, 2004).

According to Weiss (2006), Kant's categorical imperative can be divided into the following two parts. According to the first part individuals must, in any situation, choose that behaviour according to which they would like all people to behave in the same situation. According to the second part of the categorical imperative, an individual in an ethical dilemma must act in such a manner, that all involved are treated with respect, and that said individuals are treated not merely as means to an end, but as an end in themselves. Rossouw and Van Vuuren (2004) indicate that Kant's categorical imperative principle therefore force decision makers to take into account that it is their duty to behave in a responsible manner, and respectfully, towards other individuals. As soon as individuals have thus 
acquired rational insight into the universal moral law, such individuals will respect and abide by the moral authority of the universal law from a sense of duty.

\section{The principle of prohibition}

Esterhuyse (1991) states that an important function of certain moral rules is to allocate an inherent moral value to determined actions, regardless of their consequences. Such rules are normally negatively stated, such as for example, that of the Ten Commandments where a prohibition is placed on murder and theft, among others. In this regard, the divine command theory is closely related to the principle of prohibition. According to the divine command theory, God's will forms the basis for morality. The divine command theory refers not only to the Old and New Testamental God, but to the notion of God, irrespective of which religion is practiced (Rae, 1995).

According to Esterhuyse (1991) rules which fall under the principle of prohibition have a very strong prescriptive and compulsory character, and place a prohibition on certain types of actions. As a result of the prohibition character of these types of rules, a trend named moral absolutism developed, according to which rules are applied in a dogmatic manner, and no exception to the rule is allowed. The following statement provides a clear example of the means by which moral absolutists approach issues (Cargile, 1998: 64): ' ... if someone really thinks, in advance, that it is open to question whether such an action as procuring the judicial execution of the innocent should be quite excluded from consideration - I do not want to argue with him; he shows a corrupt mind'.

\section{Contractualism}

Solomon (1994) as well as Malloy and Zakus (1995) identify a further deontological approach, namely contractualism. This approach includes the establishment of a social contract, according to which the correctness of an individual's behaviour is based on the degree to which it agrees with the standards established by the community. Scanlon (1998) defines the nature of unethical behaviour from the contractualistic perspective as any behaviour which is forbidden by a set of rules.

From a business perspective, the contractual principle includes the organization, employees and consumers (community). The social contract must not only hold advantages for the organization (for example increased productivity and competitive ability in the labour market), but must simultaneously contribute to the promotion of the well-being of those responsible for the prosperity and survival of the organization, namely the employees and consumers. Contractualism, within an organizational context, therefore rests on the following three principles, namely that the organization must promote the long term welfare of employees and consumers in the society within which the organization functions; the organization may not disadvantage employees and consumers in any way; and the organization may in no way overstep the minimum standard of justice (Donaldson, 1989).

\section{Rights}

Esterhuyse (1991), Solomon (1994), Stead et al. (1994) and Weiss (2006) identify a fourth deontological approach which is based on the principle of rights. Rights can be subdivided into moral rights and legal rights. The principle of moral rights promotes individual well-being and protects the individual (Du Plessis, 1993; Stead et al., 1994). Individual freedom, prosperity, security, health and happiness form the core of moral rights. The fact that each individual has certain moral rights implies that other individuals have a duty not to violate these rights (Weiss, 2006). According to Kant (Solomon, 1994) the rights of human dignity, as well as to be treated by others as an individual in themselves and not as a means to an end, form the foundation of morality. With regard to legal rights, a system of rules which juristically sanctions moral norms is built into any legal system.

At the basis of any juristically sanctioned system lies the ground rule of justice. These types of rules therefore represent a specific society's conception regarding justice (Esterhuyse, 1991). From the aforementioned discussions of moral and legal rights it is thus apparent that, although moral rights specifically focus on the individual, and legal rights are regarded from more of a societal perspective, moral rights are indeed protected by law as certain moral norms are made juristically compulsory. Weiss (2006) also indicates that moral rights are based on both legal rights as well as a sense of duty. As moral rights refer to that which the individual is entitled to, said moral rights place an obligation on others towards the involved individual (Solomon, 1994).

The inability of employees to make decisions from a rulebound approach within the organization context may have far reaching consequences for the organization. Appelbaum and Morison (2006) state in this regard that behaviour within the organizational context is regarded as unethical should the organization's internal norms, policies or rules be transgressed by an individual or group. Desjardins (2006) states furthermore that the employee has a specific relationship with the employer. The employee is appointed to perform certain tasks and has certain commitments to the employer. The employee therefore has certain legal obligations to the employer. In this regard it appears that ethical rationalism and the principle of rights play an important role within the organizational context. Not only does the rule-bound approach play an important role during ethical decision making and the behaviour of employees, but it is also critical that employers must be able to act and take decisions from a rule-bound approach. In this 
regard, employee rights play an important role. Employee rights includes among others, the right to a minimum wage, equal opportunities and permission to belong to a union (Desjardins, 2006). Rowan (2000) states that employee rights are important, as employees are usually in a subordinate position in relation to their employers. This inequality provides the opportunity for different types of exploitation, such as inadequate remuneration, discrimination and invasion of the privacy of employees. Furthermore, employee rights are complex in the sense that management must first determine which rights are valid and then weigh them up against the rights of other interest groups, before ethical decisions can be made. Therefore, it is important that management must understand the moral foundation of employee rights.

\section{The rule-bound consequensialistic approach}

Critique levelled against both the rule-bound and consequensialistic approaches illustrate, according to Esterhuyse (1991), that moral issues cannot be managed according to watertight recipes. The most important points of critique against the rule-bound approach centre around questions regarding when a rule is the acceptable rule, whether the rules are absolute or whether they can change according to circumstances and experiences. With regards to the consequensialistic approach, the following critical question is asked, namely whether the morality of an action and decision can be determined only according to the consequences thereof. In other words, can the ends justify the means in all cases, or should the means not also be morally judged.

Esterhuyse (1991) as well as Malloy and Zakus (1995) state that the rule-bound consequensialistic approach (Figure 2), also known as the hybrid approach, was developed in response to the aforementioned critique. According to the rule-bound consequensialistic approach, the acceptability of an action or decision is determined by the question of whether it complies with a rule, while the acceptability of the rule depends on the consequences resulting from the application of the rule. Thus, the moral status and applicability of the rule is determined by the consequences thereof. Therefore, the possibility that exceptions can be made randomly is not excluded.

Employees and employers are confronted with ethical issues on a daily basis, where decisions cannot merely be guided by rules, norms or policies on the one hand, or merely by judgment of the consequences of said decisions on the other hand. In such cases, it is essential that the individual weigh rules and consequences against one another, and make a decision within the context of that specific issue. However, Esterhuyse's (1991) rule-bound consequensialistic approach still appears to be too limited as other approaches such as the virtue approach, the social justice approach and relativism among others, also play a role when rules and consequences must be weighed against one another.

\section{Virtue approach}

Plato (426-347 B.C.) and Aristotle (384-322 B.C.) are regarded as the two most prominent figures responsible for the development of the virtue approach (Figure 2). The virtue approach, also known as aretaic ethics, is derived from the Greek word 'arete' which means 'virtue'. Should focus be placed on the previous philosophical approaches regarding ethical decision making, these approaches can be classified as action-orientated ethical approaches. In contrast, the virtue approach focuses not on the action itself, but on the person conducting the action. The focus of the virtue approach is therefore on the individual's character and not on any obligation which the individual has (Rae, 1995).

According to Aristotle (1972; Garofalo, 2003), the morality of an action can also be determined by the characteristics reflected by the action. Aristotle, furthermore, is of the opinion that only those with a 'good' character are able to do good and that the development of such a character is dependent on the development of virtues (Aristotle, 1977; Rossouw and Van Vuuren, 2004; Rossouw et al., 2006). According to Rachels (1998), the virtue approach can only fully be grasped should clarity be sought regarding what makes an individual virtuous. In response to this it is important to focus on Aristotle's definition of the concept 'virtue'. Aristotle defines a virtue as 'an activity of the soul, implying a rational principle' (Aristotle, 1972: 13; Rossouw and Van Vuuren, 2004: 60).

Aristotle has a very specific vision regarding human nature. Aristotle was of the opinion that two dimensions can be distinguished in every person, namely a rational and irrational dimension, and that the rational dimension must always be the dominant dimension. Moral virtue is therefore a disposition which is under rational control of the individual. Aristotle makes use of the concept 'golden mean' in order to provide clarity regarding the term 'disposition under rational control'. The human's natural disposition is to be inclined towards one of two extremes; the individual has either too much or too little of a certain virtue. Therefore, Aristotle describes 'the golden mean' as the midpoint between an excess of, and a deficiency of, a certain disposition (Aristoteles, 1977; Rossouw and Van Vuuren, 2004; Rossouw et al., 2006). Therefore, virtuous individuals are those persons who take rational control over their lives, develop and build on their moral virtues and manage a golden mean between an excess of, and a lack of a certain human disposition (Rossouw and Van Vuuren, 2004).

From an organizational perspective, the ability of employers/ management and employees to make decisions from a virtue-based approach, and to direct their behaviour as such, is of critical importance. One of the virtues that stand out in the work context is that of honesty. Honesty 
is also one of the ethical values and virtues which is universally recognized (Desjardins and McCall, 1996). Various examples of dishonest behaviour by employees is regarded in the literature, among which are employees guilty of bribery, corruption and fraud (Gordon and Miyake, 2001; Malan and Smit, 2001), theft (Gross-Schaefer, Trigilio, Negus and Ro, 2000; Trevino and Nelson, 2007) as well as employees who are guilty of being unproductive (Malan and Smit, 2001). Apart from the virtue of honesty Dejardins and McCall (1996) also indicate that employers regard loyalty and reliability of employees as critical. An additional virtue highlighted by Malan and Smit (2001) is integrity. In this regard, Malan and Smit (2001) place specific emphasis on the integrity of managers, and indicate that managers disregard the interests of shareholders should they be dishonest, and not possess the virtue of integrity.

\section{The social justice approach}

Another main philosophical approach regarding ethical decision making, which can be distinguished from Figure 2, is the social justice approach. The social justice approach is based on the stance that each person must have an equal opportunity in life to strive for meaning and happiness (Stead et al., 1994). This approach is based on the principle of fairness and equality. An action or decision is right or wrong, acceptable or unacceptable, depending on whether it results in a fair and equal division of opportunity, as well as misfortune, for all (Weiss, 2006).

The philosopher John Rawls established two sets of rules upon which the justice principle is based. Firstly, all people must receive equal treatment and secondly, all people must, on the grounds of their position and status, have equal access to those opportunities established by society (Rawls, 1971, Chryssides and Kaler, 2005; Weiss, 2006). Although equality forms the basic premise of the justice principle, Solomon (1994) emphasizes that it does not mean that all must deserve equal treatment and equal compensation, regardless of their behaviour and input. What is of importance however is that each individual's interests will be taken into consideration regardless of irrelevant factors such as race, religion, gender and age.

Plato however provided a simplified definition of fairness. Plato defines fairness as the principle according to which all receive the legitimate part due to them, and which they deserve. Plato states furthermore that an individual's 'legitimate part', with regards to both income and honour, depends on their position in society. Plato believes that the individual's position is already cemented at birth (Plato, n.d.; Solomon, 1994). The modern viewpoint held, however, is that all must have an equal opportunity to obtain a certain position. From a business perspective, positions may vary according to status and value, as well as the need of said positions at that specific time in the labour market. In light of this, an individual's 'legitimate' part is not fixed beforehand, but is negotiable, and depends on successes and failures among others, as well as changes in the labour market (Solomon, 1994). Therefore, the following factors, among others, must be taken into account when the justice principle is applied from an organizational perspective, to determine whether individuals received their 'legitimate part', namely equality (each individual is the same); merits (the individual's actual contribution); diligence (the amount of work completed irrespective of the contribution); ability (diligence and results are weighed up against one another to determine what the person can actually do); moral virtue (to set an example or to be a 'good person', whether it has any effect on results or not); responsibility (willingness to take the blame or to make critical decisions); need (that which a person needs to be able to live comfortably and to be as productive as possible); contractual obligations (previous contracts concluded, or promises which were made, must be fulfilled, irrespective of the merits of the matter) as well as reward for risks taken (compenzation for risks taken in order to support a good case) (Solomon, 1994).

From the aforementioned discussion of the justice approach, it is apparent that this approach includes certain aspects of the rule-bound, consequensialistic as well as virtue-based approaches, in order to determine the acceptability of an action or decision.

\section{Relativism}

It is apparent from Figure 2 that relativism is another prominent philosophical approach regarding ethical decision making. Ethical relativism is based on the premise that no universally moral principles and no objective moral truths or standards exist. The acceptability or unacceptability of any action or decision is not absolute or unchanged, but relative to individual personal preferences or culture. Therefore, ethical relativism can be subdivided into ethical subjectivism and cultural relativism (Rae, 1994; Pojman, 2000; Rossouw and Van Vuuren, 2004; Weiss, 2006).

Rossouw and Van Vuuren (2004), as well as Weiss (2006), state that ethical subjectivists are of the view that individuals establish their own moral standards for the judgment of their actions. Ethical behaviour and decisions are therefore based on the individual's own subjective values (Rossouw and Van Vuuren, 2004; Weiss, 2006). According to Pojman (2000: 14) ethical subjectivists therefore hold the following standpoint: 'Morality is in the eye of the beholder'. According to ethical subjectivists each person's ethical judgments are only valid for the specific individual, and it is not applicable to other individuals, as the values upon which other people base their ethical judgments may differ (Rossouw and Van Vuuren, 2004).

In contrast to ethical subjectivists, cultural relativists are of the opinion that what is ethically correct in one culture may be unacceptable in another culture. Moral standards may vary 
between cultures as a result of each culture's own customs, practices, convictions and value structures (Weiss, 2006). Cultural relativism can be summarized in the following two standpoints. Firstly, cultural relativists are of the view that the moral acceptability or unacceptability of actions or decisions varies between cultures. Secondly, cultural relativists are of the opinion that morality does not take place in a vacuum. Therefore, cultural relativists hold the view that there are no universally valid moral principles which apply to all people regardless of their cultural context (Pojman, 2000).

The use of only a relativistic approach by employees and employers (whether cultural relativism or ethical subjectivism) without the ability to incorporate other approaches during ethical decision making may have a destructive influence on the organization. In spite of cultural and individual differences it is critical that, from an organizational perspective, certain universal moral values that can guide acceptable behaviour and decisions within organizations exist. In this regard, Rae (1995) states that although cultural differences exist, it does not mean that there are not certain universal values that apply above culture. Garofalo (2003) furthermore identifies the following ten universal values, namely honesty, accountability, loyalty, fairness, integrity, respect for others, striving for excellence, to take responsibility for citizens, to care for others and to fulfil promises. Apart from the aforementioned universal values, Malan and Smit (2001) identify certain shared values within a labour context which are found in most organizations. The following are highlighted: adaptability, transparency, to take others into account, openness, respect for all, service, incorruptibility, integrity, fairness, justice, effectiveness, impartiality, loyalty, social equality, quality, competency, accountability and diligence.

\section{THE DYNAMIC NATURE OF ETHICAL DECISION- MAKING}

As previously discussed, numerous ethical issues exist within the work context which may have serious consequences for the organization, employee and public/ consumer. In light of the negative consequences of unethical behaviour, it is important that management make a concerted effort to ensure that decision making within the organization is ethical. Therefore, it is important that renewed attention be given to those ethical decision-making approaches used in the work context.

Figure 2 represents the proposed holistic philosophical framework of ethical decision making which integrates the following six main philosophical approaches regarding ethical decision making, namely the consequensialistic approach which can be subdivided into utilitarianism (eudemonistic utilitarianism and hedonistic utilitarianism), egoism, altruism and vitalism; the rule-bound approach which can be subdivided into ethical rationalism, the principle of prohibition, contractualism and rights; the rule-bound consequensialistic approach; the virtue based approach; the social justice approach and relativism which can be further subdivided into ethical subjectivism and cultural relativism.

When individuals are confronted with ethical issues in the workplace they may use one or more of the aforementioned decision-making approaches. Some individuals may be inclined to use the same approach throughout, while other individuals may follow a more holistic perspective, where the approach followed is determined by the specific situation and ethical issue which they are confronted with. Gray (1996) states in this regard that a holistic view of morality takes all aspects of morality into account, including moral rules and principles, duties and responsibilities, consequences, moral sensitivity, moral consciousness, moral reflection and moral commitment. From a holistic perspective moral reasoning acquires a dynamic character, and is no longer viewed as a static and unchanged process.

\section{CONCLUSION AND RECOMMENDATIONS}

The focus of this article was firstly to investigate the predominant ethical issues which organizations face as well as the various philosophical decision-making approaches that may influence ethical decision making in the work context, and to integrate these approaches within a holistic framework of ethical decision making. General ethical issues in the work place were indentified with specific focus on: the organization and the consumer, community and shareholders; the organization and the environment; ethical issues arising from the organization/management employee interaction as well as ethical issues arising from the employee - organization/management interaction. Regarding the philosophical approaches to ethical decision making, six main philosophical approaches regarding ethical decision making together with their sub-approaches were identified and integrated within a holistic framework of philosophical approaches that influence ethical decision making.

As unethical behaviour is negative and destructive for any organization, employers should not only be aware of the various ethical issues that need to be faced on a daily basis, but should also be aware of the ethical approaches which are followed by the organization, as well as individual employees during ethical decision making when faced with these issues Since ethical decision making may be approached from various philosophical perspectives, seemingly based on the specific ethical issue, it seems imperative that organizations should formulate ethical guidelines based on moral consensus regarding right and wrong, in order to guide the organization and individual organization members in ethical decision making.

It will be particularly important within the organizational context that organizations and employees be able to direct 
their behaviour and decision making from a rule-bound approach in order to create a shared set of values and rules which should guide ethical decision making within the organization. In the case of managers, the type of issue with which management is confronted requires not only that focus be placed on the rules or the consequences of decisions, but that a holistic perspective which takes all the approaches into account be followed. However, the first step would be to enable management to identify the dominant approaches of ethical decision making utilized at both organizational and individual levels when making decisions. This would further enable them not only to decide on the most appropriate way of dealing with ethical decision making in the work place, but will also be of assistance in the selection of new recruits in order to ensure that the basis of their ethical decision making is in line with what the organization requires.

The following recommendations for future research, as well as for practical applications of this study, are therefore suggested. Firstly, to develop and statistically evaluate a measurement model based on the philosophical approaches regarding ethical decision making. Secondly, to develop a measurement instrument based on the above-mentioned measurement model in order to enable management to identify the current approaches of ethical decision making utilized within their specific organization at both organizational and individual levels, as well as measuring the level of ethical behaviour within the organization and individuals. During the application of the measuring instrument the validity of the ethical decision-making approaches will also become evident. Thirdly, to make organizational members aware of their own ethical decisionmaking approaches by giving them feedback on their most dominant ethical decision-making approach(es) with specific emphasis on the advantages and disadvantages which this said approach may hold during ethical decision making. Fourthly, to develop and implement interventions in order to improve ethical behaviour in organizations.

\section{REFERENCES}

Appelbaum, S.H. \& Shapiro, B.T. 2006. Diagnosis and Remedies for Deviant Workplace Behaviors. The Journal of American Academy of Business, 9(2): 14-20.

Aristotle. 1972. The Nicomachean Ethics of Aristotle (translated by D. Ross). London: Oxford University Press.

Aristotle. 1977. The Ethics of Aristotle: The Nicomachean Ethics. (translated by J.A.K. Thomson, revised by H. Tredennick). England: Penguin Books. Ashley, P., Powers, C. \& Schunter, M. 2002. From Privacy Promises to Privacy Management. Proceedings of the 2002 workshop on New security paradigms, Virginia Beach, Virginia.

Babbie, E. \& Mouton, J. 2004. The practice of social research. Cape Town: Oxford University Press.

Bandura, A. 1977. Social Learning Theory. Englewood Cliffs, New Jersey: Prentice-Hall.

Boshoff, E. 2009. Die ontwikkeling van 'n werksetiekvraelys gebaseer op 'n holistiese filosofiese model van etiese bes/uitneming. Unpublished doctoral thesis, University of the Free State, Bloemfontein.

Cargile, J. 1998. On Consequentialism. In J. Rachels (ed.) Ethical Theory
2: Theories About How We Should Live. Oxford: Oxford University Press. Cascio, W.F. 2003. Managing Human Resources: Productivity, Quality of Work Life, Profits (6 $6^{\text {th }}$ ed.). New York: McGraw-Hill.

Chryssides, G.D. \& Kaler, J.H. 2005. An Introduction to Business Ethics. London: Thomson Learning.

Cialdini, R.B., Petrova, P.K. \& Goldstein, N.J. 2004. The Hidden Costs of Organisational Dishonesty. MIT Sloan Management review, 67-73.

De Koker, L. 2007. Financial Crime in South Africa. Economic Affairs, 27(1): 34-38.

Desjardins, J. 2006. An Introduction to Business Ethics (2 ${ }^{\text {nd }}$ ed.). Boston: McGraw-Hill.

Desjardins, J.R. \& McCall, J. 1996. Contemporary Issues in Business Ethics ( $3^{\text {rd }}$ ed.). Belmont: Wadsworth Publishing Company.

Donaldson, T. 1989. The Ethics of International Business. Oxford: Oxford University Press.

Donaldson, J. 1992. Business Ethics: A European Casebook. London: Academic Press Inc.

Du Plessis, J.O. 1993. Die Bestuur van Sake-Etiek in die Bankwese. Unpublished masters dissertation. Bloemfontein: University of the Free State.

Economic crime: people, culture and controls. 2007. Price Waterhouse Cooper's: The $4^{\text {th }}$ biennial Global Economic Crime Survey South Africa. South Africa: Price Waterhouse Coopers.

Esterhuyse, W. 1991. Sake-etiek in die Praktyk. Pretoria: J.L. van Schaik (Edms.) Bpk.

Evans, R. HIRING ON HIGH: Ethics an essential part of the hiring process for property managers. Journal of Property Management. [Online]. Available:http://web.ebscohost.com/ehost/pdfviewer/ pdfviewer?sid =04618d82-b603-42a9-8718-e74bc57dc136\%40sessionm gr115\&vid=5\&hid=126_. Accessed on 27 February 2009.

Freeman, R.E. 1991. Business Ethics: The State of the Art. New York: Oxford University Press.

Garofalo, C. 2003. Toward a global ethic: Perspectives on values, training and moral agency. International Journal of Public Sector Management, 16(7): 490-501.

Garriga, E. \& Melé, D. 2004. Corporate Social Responsibility Theories: Mapping the Territory. Journal of Business Ethics, 53: 51-71.

Gewirtz, J.L. \& Peláez-Nogueras, M. 1991. Proximal Mechanisms Underlying the Acquisition of Moral Behaviour Patterns. In W.M. Kurtines \& J.L. Gewirtz (eds.) Handbook of Moral Behaviour and Development. Hillsday, New Jersey: Lawrence Erlbaum Associates, Inc., Publishers.

Gibson, K. 2007. Ethics and Business: An Introduction. New York: Cambridge University Press.

Gloek, J.D. \& De Jager, H. 2005. Fraud Profiles of public sector institutions in South Africa. Southern African Journal of Accountability and Auditing Research, 6: 49-65.

Gordon, K. \& Miyake, M. 2001. Business Approaches to Combating Bribery: A Study of Codes of Conduct. Journal of Business Ethics, 34: 161-173.

Gray, M.M.A. 1996. Moral Theory for Social Work. Social Work, 32(4): 289-295.

Grobler, P.A., Wärnich, S., Carrell, M.R., Elbert, N.F. \& Hatfield, R.D. 2002. Human Resource Management in South Africa (2 ${ }^{\text {nd }}$ ed.). London: Thomson Learning.

Gross-Schaefer, A., Trigilio, J., Negus, J. \& Ro, C.S. 2000. Ethics Education in the Workplace: An Effective Tool to Combat Employee Theft. Journal of Business Ethics, 26: 89-100.

Hosmer, L.T. 1991. The Ethics of Management ( $3^{\text {rd }}$ ed.). Chicago: McGrawHill Companies, Inc.

James, H. 2002. When is a Bribe a Bribe? Teaching a Workable Definition of Bribery. Teaching Business Ethics, 6: 199-217.

Kant, I. 1937. Fundamental Principles of the Metaphysics of Ethics (translated by T.K. Abbott). London: Longmans, Green and Co. Ltd.

Kline, J.M. 2005. Ethics for International Business: Decision making in a global political economy. London: Routledge.

Malan, F. \& Smit, B. 2001. Ethics and Leadership in Business and Politics. Lansdowne: Juta.

Malloy, D.C. \& Zakus, D.H. 1995. Ethical Decision Making in Sport 
Administration: A Theoretical Inquiry into Substance and Form. Journal of Sport Management, 9: 36-58.

Marette, S., Bureau, J.C. \& Gozlan, E. 2000. Product Safety Provision and Consumers' Information. Australian Economic Papers, University of Adeleide and Flinders University of South Australia.

McCall, J.J. 2006. Deceptive Advertising. In F. Allhoff, \& A. Vaidya (eds.) Business Ethics (Volume III). London: SAGE Publications.

Meyer, W.F., Moore, C. \& Viljoen, H.G. 1988. Persoonlikheidsteorieë van Freud tot Frankl. Johannesburg: Lexikon Uitgewers (Edms.) Bpk.

Meyer, W.F., Moore, C. \& Viljoen, H.G. 2000. Personologie: Van Individu tot Ekosisteem. Sandton: Heinemann Voortgesette Onderwys (Edms.) Bpk.

Möller, A. 1993. Perspektiewe oor Persoonlikheid. Durban: Butterworth Uitgewers (Edms.) Bpk.

Neubeck, K.J. \& Glasberg, D.S. 1996. Sociology: A Critical Approach. New York: McGraw-Hill, Inc.

Orme, G. \& Ashton, C. 2003. Ethics - a foundation competency. Industrial and Commercial Training, 35(5): 184-190.

Parsons, P.J. 2007. Ethics in Public Relations: A Guide to Best Practice. London: Kogan Page Limited.

Plato wrote this in the time period "Before Christ": As with Aristotle, Plato's initials are unknown. It is not indicated in the book when it was translated. Therefore the reference stays: Plato. (no date). The Republic of Plato ( $2^{\text {nd }}$ ed.) (translated by A.D. Lindsay). London: J.M. Dent \& Co.

Pojman, L.P. 2000. Life and Death: Grappling with the Moral Dilemmas of Our Time ( $2^{\text {nd }}$ ed.). Belmont, CA: Wadsworth Publishing Company.

Rabl, T. \& Kühlmann, T.M. 2008. Understanding Corruption in Organisations - Development and Empirical Assessment of an Action Model. Journal of Business Ethics, 82: 477-495.

Rachels, J. 1998. Ethical Theory 2: Theories About How We Should Live. Oxford: Oxford University Press.

Rae, S.B. 1995. Moral Choices: An Introduction to Ethics. Grand Rapids, Michigan: Zondervan Publishing House.

Rand, A. 1964. The Virtue of Selfishness: A New Concept of Egoism. New York: The New American Library, Inc.

Rawls, J. 1971. A Theory of Justice. Cambridge, Massachusetts: Harvard University Press.

Rossouw, D. 2002. Business Ethics in Africa ( $2^{\text {nd }}$ ed.). Cape Town: Oxford University Press.

Rossouw, D., Prozesky, M., Van Heerden, B. \& Van Zyl, M. 2006. Ethics for Accountants and Auditors. Cape Town: Oxford University Press.

Rossouw, D. \& Van Vuuren, L. 2004. Business Ethics ( $3^{r d}$ ed.). Cape Town: Oxford University Press Southern Africa.

Rowan, J.R. 2000. The Moral Foundation of Employee Rights. Journal of Business Ethics, 24: 355-361.
SA capital of white-collar crime. October 16, 2007. Mail and Guardian. [Online]. Available: http://www.mg.co.za/article/2007-10-16-sa-capital-ofwhitecollar-crime. Accessed on 27 February 2009.

Scanlon, T.M. 1998. Contractualism and Utilitarianism. In J. Rachels (ed.) Ethical Theory 2: Theories About How We Should Live. Oxford: Oxford University Press.

Schweitzer, A. 1929. Civilization and Ethics (The Philosophy of Civilization Part II) (translated by C.T. Campion). London: A. and C. Black, Ltd.

Skinner, B.F. 1965. Science and Human Behavior. London: CollierMacMillan.

Solomon, R.C. 1994. Above the Bottom Line: An Introduction to Business Ethics ( $2^{\text {nd }}$ ed.).

Orlando: Harcourt Brace College Publishers.

Sorrel, T. \& Hendry, J. 1994. Business Ethics. Oxford: Butterworth-Heinemann.

Squire, D. 2007. Corporate Governance and Ethical Behaviour. [Online]. Available: http://www.ruff.co.za/print/5390_CORPORATE_GOVERNANCE_ AND_ETHICAL_BEHAVIOUR.htm. Accessed on 27 February 2009.

Staub, E.N.D. The Roots of Goodness: The Fulfilment of Basic Human Needs and the Development of Caring, Helping and Non-aggression, Inclusive Caring, Moral Courage, Active Bystandership and Altruism Born of Suffering. University of Massachusetts, Amherst.

Stead, W.E., Worrel, D.L. \& Stead, J.G. 1994. An integrative model for understanding and managing ethical behaviour in organisations. In J. Drummond, \& B. Bain (eds.) Managing Business Ethics. Oxford: Butterworth-Heinemann Ltd.

Svensson, G. \& Wood, G. 2003. The dynamics of business ethics: A function of time and culture-cases and models. Management Decision, 41(4): 350-361.

Swanepoel, B., Erasmus, B., Van Wyk, M. \& Schenk, H. 2003. South African Human Resource Development: Theory and Practice ( $3^{\text {rd }}$ ed.). Lansdowne: Juta.

Trevino, L.K. \& Nelson, K.A. 2007. Managing Business Ethics: Straight Talk About How To Do It Right (4th ed.). USA: John Wiley and Sons, Inc.

Van Zyl, E.S., \& Boshoff, E. 2010. The relationship between ethical behaviour and self-concept amongst a group of secondary school teachers in the Northern Cape. Acta Criminologica, 23(3): 40-52.

Weiss, J.W. 1998. Business Ethics: A Stakeholder and Issues Management Approach ( $2^{\text {nd }}$ ed.). Orlando: Harcourt Brace College Publishers.

Weiss, J.W. 2006. Business Ethics: A Stakeholder and Issues Management Approach ( $2^{\text {nd }}$ ed.). Mason, Ohio: Thomson/South-Western.

How to cite this article: ???

Source of Support: Nil, Conflict of Interest: None declared

\section{AUTHORS}

Dr. Boshoff holds a PhD from the University of the Free State (UFS). As part of her PhD she developed a Work Ethics Questionnare which determines individuals' ethical decision-making approaches as well as their level of ethical behaviour. She is a registered Industrial Psychologist and is employed by the UFS as a lecturer. She teaches Research Methodology and is coordinator of the Honours Programme. Her focus areas are Ethics, Psychometric Assessment (with the focus on Medical-Legal Assessment) and Research Methodology. Dr Boshoff received two best paper awards from the Clute Institute for Academic Research for papers delivered at the 2008 and 2009 Business and Economics Conferences in Rothenberg, Germany and in Prague.

Prof. Kotzé is currently employed as an Associate Professor at the University of the Free State in Bloemfontein, South Africa. She is responsible for the development and presentation of various undergraduate and post graduate courses and research in the Department of Industrial Psychology, University of the Free State (UFS) Business School, as well as at the Centre for Business Dynamics. Currently, her main focus areas are Organisation Psychology, Organisation Development, Self development, and Leadership development. Prof Kotzé is also registered as an Industrial Psychologist at both the South African Health Professions Council (HPCSA) and the British Psychological Society. She has held various training and development positions in both parastatal and private organisations, and has acted as a senior management and organisation development consultant. She still consults on a regular basis. 
Reproduced with permission of the copyright owner. Further reproduction prohibited without permission. 